\title{
Subcellular distribution of protein kinase C isozymes during cardioplegic arrest
}

\author{
Źivojin S. Jonjev, MS, MD ${ }^{a, b}$ \\ Dorie W. Schwertz, $\mathrm{PhD}^{\mathrm{C}}$ \\ Jennifer M. Beck, BS \\ James D. Ross, $\mathrm{BA}^{\mathrm{c}}$ \\ William R. Law, $\mathrm{PhD}^{\mathrm{a}, \mathrm{b}}$
}

\footnotetext{
From the Research Service, ${ }^{a}$ West Side Veterans Administration Medical Center, Chicago, Ill, the Department of Physiology and Biophysics, ${ }^{\mathrm{b}}$ University of Illinois at Chicago, Chicago, Ill, and the Department of Surgical Nursing, ${ }^{\mathrm{c}}$ University of Illinois at Chicago, Chicago, Ill.

Funding for this work was provided by a Merit Review grant from the Veterans Administration (W.R.L.)

Received for publication Feb 28, 2003; revisions requested May 28, 2003; revisions received June 13, 2003; accepted for publication July 10, 2003.

Address for reprints: William R. Law, PhD, University of Illinois at Chicago, Department of Physiology and Biophysics (MC 901), 835 S Wolcott Ave, Chicago, IL 60612-7342 (E-mail: wrlaw@uic.edu).

J Thorac Cardiovasc Surg 2003;126:1880-5

Copyright (๑) 2003 by The American Association for Thoracic Surgery

$0022-5223 / 2003 \$ 30.00+0$

doi:10.1016/S0022-5223(03)01326-6
}

Background: On the basis of the hypothesis that cardioplegia-associated myocardial depression was due to activation of protein kinase $\mathrm{C}$, we examined whether specific protein kinase $\mathrm{C}$ isozymes would translocate to a cellular fraction containing myofilaments.

Methods: Isolated rat hearts were perfused with Krebs-Ringer bicarbonate buffer for 30 minutes and arrested with $4^{\circ} \mathrm{C}$ St Thomas No. 2 cardioplegic solution for 0 to 120 minutes ( $\mathrm{n}=5$ per group). The 3 fractions of the left ventricle tissue represented the myofibrillar/nuclear fraction (P1), membranes (P2), and cytosol (supernatant). The distributions of protein kinase $\mathrm{C}$ isozymes $\alpha, \delta, \epsilon$, and $\eta$ were examined after separation by electrophoresis, immunoblotting/chemiluminescence, and densitometry.

Results: A significant increase in protein kinase $\mathrm{C}-\delta$ in the $\mathrm{P} 1$ fraction was detected after 5 minutes of cardioplegic arrest and remained increased for 60 minutes. Increases in P1 protein kinase C- $\alpha$ and $-\epsilon$ were seen transiently at 5 minutes, and protein kinase C- $\epsilon$ demonstrated a secondary increase in P1 at 30 to 60 minutes. There was also a significant relative increase in protein kinase $\mathrm{C}-\alpha$ and protein kinase $\mathrm{C}-\delta$ in the $\mathrm{P} 2$ fraction after 60 minutes of cardioplegia.

Conclusions: These data are consistent with our hypothesis that activation of protein kinase $\mathrm{C}$ isozymes is associated with altered myofilament function after cardioplegic arrest.

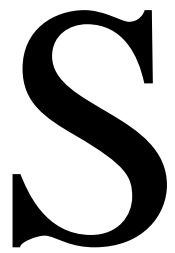

table patients presenting for elective heart operations (eg, coronary bypass surgery) usually face a low risk of perioperative morbidity and mortality. However, cardiac surgery is being performed on increasingly unstable, complex patients who have other risks, such as advanced age or additional illnesses. Patients with poor left ventricular function and diabetic patients have been identified as those who could benefit from improved cardioprotective techniques. ${ }^{1,2}$ Ventricular dysfunction, reflected by low systolic and diastolic function and, consequently, low cardiac output, is one of the major causes for prolonged hospital stay and increased treatment costs. ${ }^{3,4}$ The primary mechanism of myocardial depression after cold crystalloid cardioplegia (CPDL) is still unclear. Many different factors have been identified as harmful and detrimental, including hypothermia alone, which, although it exerts a protective effect, can also alter enzyme kinetics and receptor-binding characteristics. Previous work from our laboratory has demonstrated that altered cellular function results from the CDPL itself, rather than as a result of reperfusion injury. ${ }^{5} \mathrm{We}$ also demonstrated that unique isozyme changes in protein kinase $\mathrm{C}$ (PKC) may be involved. The translocation and activation of PKC isozymes during ischemia and ischemic preconditioning have been associated with protection from ischemic 
injury ${ }^{6-8}$ Some isozymes of PKC, however, can have detrimental effects on cardiac function. ${ }^{9}$ Our previous work ${ }^{10}$ and that of other investigators ${ }^{6,11}$ has demonstrated that novel PKC isozymes $(\delta, \epsilon, \eta$, and $\mu$ ) may be important in myocardial signal transduction during CDPL arrest. However, the timing of events, the category of isozymes, their location, and the specificity of the response remain unclear. The aim of this study was to determine when and where specific PKC isozymes translocate among different subcellular fractions during CDPL arrest.

\section{Materials and Methods}

The experiments reported herein were approved by the Animal Care and Use Committee of the University of Illinois and conform to the Guide for the Care and Use of Laboratory Animals published by the US National Institutes of Health (Publication No. 85-23, revised 1996).

\section{Isolated Heart Protocol}

Male Sprague-Dawley rats (300-400 g) were anesthetized with sodium pentobarbital $(50 \mathrm{mg} / \mathrm{kg}$ intraperitoneally). A midline abdominal incision was made, and sodium heparin (200 IU) was injected into the inferior vena cava. Two minutes after injection of heparin, the chest was rapidly opened, and the heart was removed and placed in ice-cold $\left(4^{\circ} \mathrm{C}\right)$ Krebs-Ringer bicarbonate buffer. Extraneous tissue was dissected free, and the aortic root was rapidly cannulated. The cannula was then connected to a nonrecirculating, temperature-controlled, isolated heart perfusion apparatus. The heart was perfused with warm $\left(37^{\circ} \mathrm{C}\right)$, oxygenated (95.5\% oxygen $/ 4.5 \% \quad \mathrm{CO}_{2}$ ), modified Krebs-Ringer bicarbonate buffer (pH 7.4) containing $100 \mathrm{mmol} / \mathrm{L} \mathrm{NaCl}, 4.74 \mathrm{mmol} / \mathrm{L} \mathrm{KCl}$, $1.12 \mathrm{mmol} / \mathrm{L} \mathrm{CaCl}_{2}, 1.18 \mathrm{MgSO}_{4}, 25 \mathrm{mmol} / \mathrm{L} \mathrm{NaHCO}_{3}$, and 1.18 $\mathrm{mmol} / \mathrm{L} \mathrm{KH}_{2} \mathrm{PO}_{4}$ and modified with the addition of $11.4 \mathrm{mmol} / \mathrm{L}$ glucose, $4.92 \mathrm{mmol} / \mathrm{L}$ pyruvate, and $5.38 \mathrm{mmol} / \mathrm{L}$ fumarate. The hearts were perfused in an aortic retrograde fashion at a constant pressure of $80 \mathrm{~mm} \mathrm{Hg}$ and paced at 300 beats/min with bipolar stainless-steel electrodes embedded in the right atrium.

\section{Research Design}

Left ventricular pressures were recorded as previously detailed ${ }^{10,12}$ via a latex balloon inserted into the left ventricle. The preparation was considered stable if the diastolic and systolic pressures remained constant (diastolic pressure variation $<2 \mathrm{~mm} \mathrm{Hg}$ and systolic variation $<5 \mathrm{~mm} \mathrm{Hg}$ ) for 15 minutes. Systolic developed pressure at a preload pressure of $5 \mathrm{~mm} \mathrm{Hg}$ was used to compare systolic performance between groups. Each heart was perfused for 30 minutes at $37^{\circ} \mathrm{C}$ (stabilization period). Exclusion criteria included ventricular dysrhythmias, inability to capture pacing of the heart, or low systolic pressure $(<60 \mathrm{~mm} \mathrm{Hg}$ ) during the equilibration period. If any of these criteria were present, the heart was excluded from the study.

Signal-induced activation and translocation of PKC occurs rapidly and is followed by the functional response. Translocation of different PKC isozymes may not occur simultaneously. Thus, to capture CDPL-elicited changes in isozyme distribution, hearts undergoing CDPL arrest were quickly frozen in liquid nitrogen after various durations of arrest. After completion of the protocol, only the left ventricle was dissected free and quickly frozen in liquid nitrogen for later assessment of PKC levels in particulate and cytosolic fractions by immunoblotting, as described below. Left ventricles from the no-perfusion hearts were frozen immediately after removal from the chest.

\section{Experimental Groups}

Rats were randomly assigned to 1 of 7 experimental groups $(\mathrm{n}=$ 5 per group). The first group of hearts was a nonperfused group. Hearts were taken out of the chest and quickly frozen in the liquid nitrogen, without perfusion. The other 6 groups of hearts underwent isolated heart perfusion with Krebs-Ringer bicarbonate buffer for a 30-minute baseline period. Krebs-Ringer bicarbonate buffer was oxygenated throughout the procedure with $95.5 \%$ oxygen and $4.5 \% \mathrm{CO}_{2}$ and maintained at $37^{\circ} \mathrm{C}(\mathrm{pH}$ 7.4). After baseline perfusion, hearts were arrested with $3 \mathrm{~mL}$ of cold, crystalloid St Thomas No. 2 cardioplegia $(643 \mathrm{mg} / \mathrm{L} \mathrm{NaCl}, 119.3 \mathrm{mg} / \mathrm{L}$ $\mathrm{KCl}, 17.6 \mathrm{mg} / \mathrm{L} \mathrm{CaCl}_{2}, 325.3 \mathrm{mg} / \mathrm{L} \mathrm{MgCl}_{2}$, and $10 \mathrm{~mL} / \mathrm{L} 8.4 \%$ $\mathrm{NaHCO}_{3}$ for $\mathrm{pH}$ adjustment to $\mathrm{pH} 7.8$ at $4{ }^{\circ} \mathrm{C}$; Abbot Laboratories, North Chicago, Ill) in a volume of $3 \mathrm{~mL}$. This was repeated every 15 minutes in the amount of $1 \mathrm{~mL}$ for up to 120 minutes. The amount of cardioplegia, time of administration, and duration of arrest closely simulate the approach taken in the operating room during heart operations. Groups of hearts at 0, 2.5, 5, 15, 30, and 120 minutes after arrest were rapidly frozen with liquid nitrogencooled aluminum tongs.

\section{Left Ventricle Tissue Preparation}

Frozen left ventricular tissue was pulverized with a pestle in an ice-cold ceramic dish under liquid nitrogen. The powdered tissue sample was then placed into $9 \mathrm{~mL}$ of homogenizing buffer containing $10 \mathrm{mmol} / \mathrm{L}$ Tris-HCI, $1 \mathrm{mmol} / \mathrm{L}$ ethylene glycol-bis $(\beta$ aminoethyl ether)- $N, N, N^{\prime}, \mathrm{N}^{\prime}$-tetraacetic acid, $350 \mathrm{mmol} / \mathrm{L}$ sucrose, $5 \mathrm{mmol} / \mathrm{L}$ sodium azide $\left(\mathrm{NaN}_{3}\right), 10 \mathrm{mmol} / \mathrm{L}$ mercaptoethanol, 0.02 $\mathrm{mmol} / \mathrm{L}$ phenylmethylsulphonyl fluoride, $50 \mathrm{mmol} / \mathrm{L} \mathrm{NaF}, 1$ $\mu \mathrm{g} / \mathrm{mL}$ pepstatin, and $1 \mu \mathrm{g} / \mathrm{mL}$ leupeptin $\left(\mathrm{pH} 7.5\right.$ at $4^{\circ} \mathrm{C}$ ) and homogenized on ice with an Omni Polytron homogenizer (probe size, $795 \mathrm{~mm}$ ) $6 \times 10$-second bursts separated by 10 -second rests. Differential centrifugation at $1000 \mathrm{~g}\left(10\right.$ minutes; $\left.4^{\circ} \mathrm{C}\right)$ and $100,000 \mathrm{~g}\left(60\right.$ minutes; $\left.4^{\circ} \mathrm{C}\right)$ yielded pellets representing a myofibrillar/nuclear fraction (P1) and nonnuclear membranes (P2), respectively; the supernatant $(\mathrm{S})$ represented the cytosolic fraction. $\mathrm{P} 1$ and $\mathrm{P} 2$ pellets were resuspended in homogenizing buffer with 48 and $24 \mu \mathrm{g} / \mathrm{mL}$ phenylmethylsulphonyl fluoride, respectively. The purity of the fractions was determined by distribution of lactate dehydrogenase, 5'-nucleotidase, or DNA (Sigma Diagnostics, St Louis, Mo).

\section{Immunoblot Analysis of PKC Isozymes}

Primary antibodies to PKC isozymes $\delta, \epsilon, \alpha$, and $\eta$ were obtained from Santa Cruz Biotechnology (Santa Cruz, Calif). These antibodies were tested against corresponding, pure PKC isozyme protein by Western immunoblot analysis. No cross-reactivity between these isozyme antibodies and other isozymes was seen.

Protein $(50 \mu \mathrm{g})$ from each fraction (P1, P2, and S) was separated by standard sodium dodecyl sulfate polyacrylamide $(7.5 \%)$ gel electrophoresis at a constant voltage according to the method of Laemmli, ${ }^{13}$ and proteins were electrophoretically transferred to 


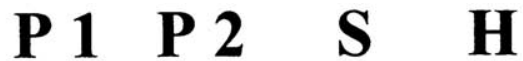

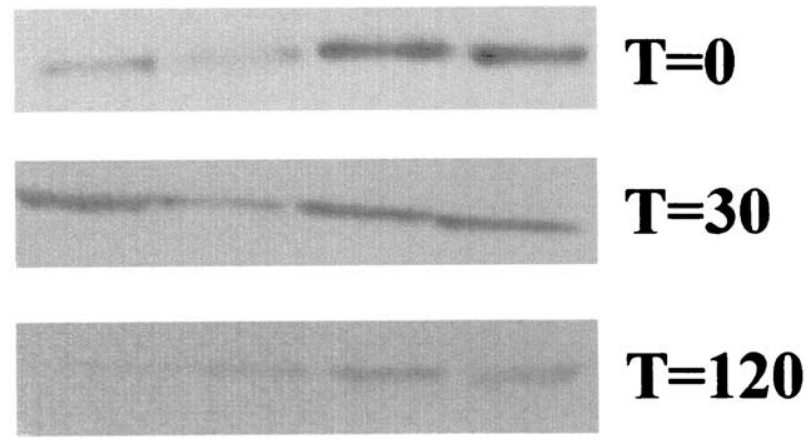

Figure 1. Representative Western blots for PKC- $\delta$ from cardiac ventricular tissue separated into the particulate fractions P1 (nucleus and myofibrils), P2 (other membranes), S (cytosol), and H (total homogenate).

nitrocellulose membranes (Hybond ECL; Amersham, Arlington Heights, Ill), as previously described. ${ }^{10}$ Standard procedures were used for immunodetection of PKC isozymes by specific antibodies to PKC $\delta, \epsilon, \alpha$, or $\eta$ (Santa Cruz Biotechnology). The identity of the PKC was confirmed by reported molecular weights and by comparison to the migration of authentic PKC in rat brain or PKC isozyme standards (Calbiochem, La Jolla, Calif). Immunoblots were scanned and quantified by relative optical density by using the computer software Un-Scan It gel, Automated Digitizing System, version 5.1 (Silk Scientific Corp, Orem, Utah). Optical densities were normalized to stable proteins visualized with Ponceau stain. The amount of isoforms present in all fractions was expressed as a percentage of isoforms from the total homogenate, which represents combined isozymes.

\section{Statistics}

All values are presented as means \pm SEM. Data were analyzed by 2 -way analysis of variance. Where the $\mathrm{F}$ value indicated significance, specific differences were determined by using the StudentNewman-Keuls post hoc test.

\section{Results}

\section{Hemodynamic Data}

Left ventricular systolic pressure was measured in the isolated perfused heart at a constant preload of $5 \mathrm{~mm} \mathrm{Hg}$ end-diastolic pressure. Systolic pressure measurements were obtained during the stabilization period at 0,15 , and 30 minutes. There were no statistically significant differences in developed systolic pressure between the groups at any point of stabilization.

\section{Subcellular Fraction Purity}

The P1 fraction displayed a Western electrophoretic protein profile identical to that seen for pure, isolated myofilaments. ${ }^{14}$ This profile was not seen in the other fractions. The P2 fraction was $>95 \%$ enriched for 5'-nucleotidase; no significant 5'-nucleotidase activity was measured in either the $\mathrm{P} 1$ or $\mathrm{S}$ fractions. The $\mathrm{S}$ fraction was $>95 \%$ enriched for lactate dehydrogenase; no significant lactate dehydrogenase activity was measured in either the P1 or the P2 fractions. Evidence of DNA was found in all fractions with no evidence of compartmentalization. This suggested that the nuclei were disrupted in the homogenization process.

\section{Change in PKC Isozyme Distribution During Cardioplegic Arrest}

The relative distribution of all PKC isozymes identified in hearts undergoing the 30-minute equilibration period alone (0 minutes of CDPL) and in unperfused hearts (fresh frozen from the chest in situ) were the same. The isozymes were primarily found in the cytosolic fraction, with $<10 \%$ in P1 and P2 fractions (Figure 1).

Representative immunoblots for PKC- $\delta$ from 3 time periods are shown in Figure 1. Densitometric data from all hearts representing the distribution of PKC isozymes $\alpha, \delta$, and $\epsilon$ in particulate fractions (P1 and P2) and cytosol (S) are shown in Figure 2. We identified significant increases in PKC- $\alpha,-\delta$, and $-\epsilon$ in the P1 fractions, with a concomitant decrease in the cytosolic fraction 5 minutes after CDPL arrest. For PKC- $\delta$, the increase in P1 was sustained through 60 minutes of CDPL. By 10 minutes, both PKC- $\alpha$ and PKC- $\epsilon$ returned to a baseline distribution pattern. PKC- $\epsilon$ demonstrated translocation to the $\mathrm{P} 1$ fraction a second time from 30 to 60 minutes. There was a small but significant relative increase in PKC- $\alpha$ and PKC- $\delta$ into the P2 fraction after 60 minutes of CDPL. We were unable to detect PKC- $\eta$ in any fraction from the rat heart.

By 120 minutes of CDPL arrest, the patterns of distribution for all PKC isozymes were similar to the basal state $(t=0)$. This most likely reflected the relative loss of PKC after activation. A decrease in optical densities in particulate fractions was seen by 120 minutes, but without a concomitant increase in cytosolic fraction density (Figure 1). Similarly, the total optical density of PKC- $\epsilon$ showed a significant decrease of PKC protein over time (Figure 3), suggesting that the relative decrease in particulate fraction PKC and the relative increase in the cytosolic fraction represented ubiquidation rather than translocation back into the cytosol.

\section{Discussion}

The results of this study indicate that during CDPL, the PKC- $\alpha, \delta$, and $\epsilon$ isozymes translocate, primarily to a portion of the myocardium represented by the myofilaments. There was also evidence of a smaller, secondary translocation of PKC- $\alpha$ and $\delta$ to the fraction containing membranes. Further, the temporal profiles of these isozyme translocations varied significantly among the isozymes. This contrasts with results seen under other conditions, such as warm ischemia 


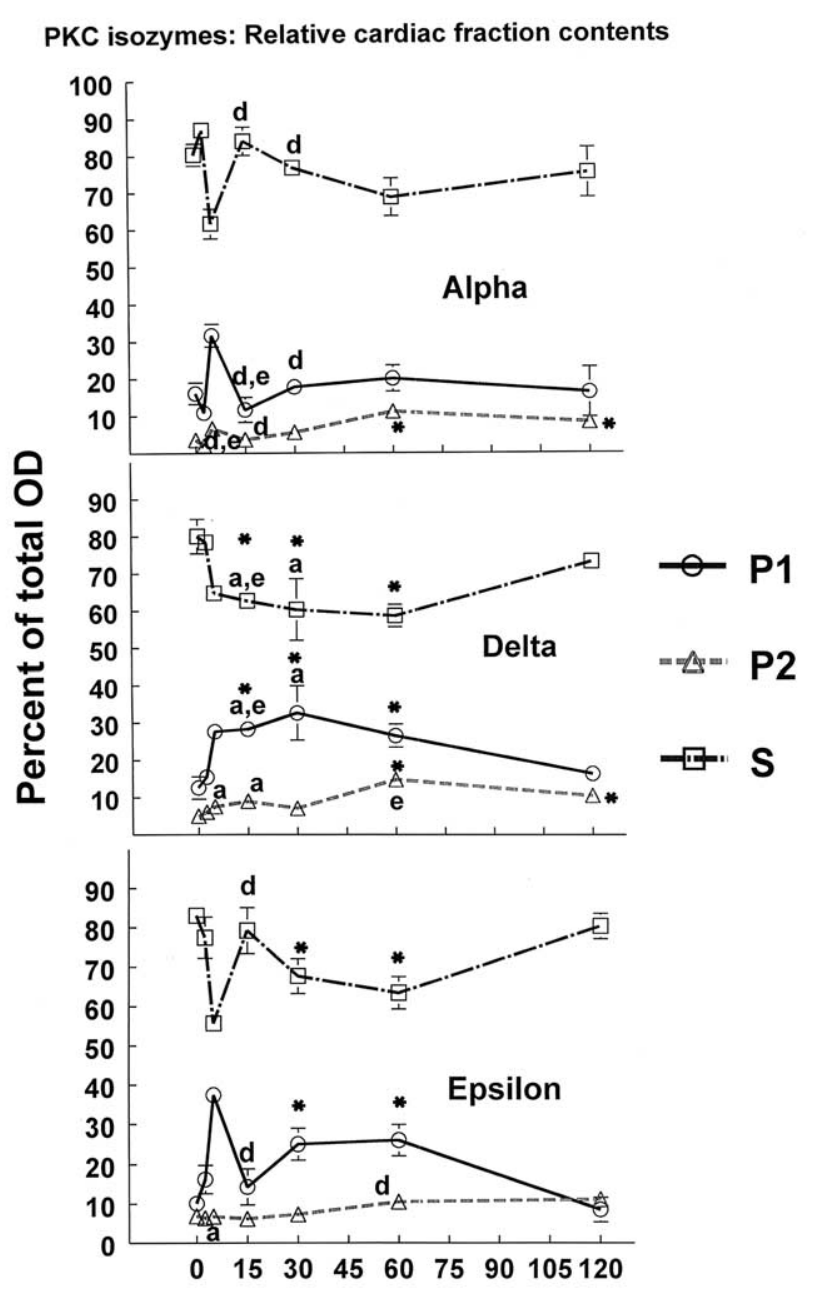

Figure 2. Subcellular distribution of PKC- $\alpha$ (top), $-\delta$ (middle), and $\boldsymbol{\epsilon}$ (bottom) at periods during cardioplegic arrest. *Different from baseline ( $t=0$ minutes); adifferent from time-matched $\alpha$ value; ddifferent from time-matched $\delta$ value; edifferent from timematched $\epsilon$ value. OD, Optical density.

and ischemic preconditioning, as reported by other laboratories, and may represent a novel response to cold.

The timing and relative quantity of subcellular redistribution of PKC isozymes during CDPL arrest were unique for each of the isozymes visualized. All isozymes visualized translocated to the fraction containing myofilament proteins at 5 minutes. This was sustained for a longer period of time only by the PKC- $\delta$ isozyme, although a secondary increase in PKC $-\epsilon$ to the P1 fraction was evident between 30 and 60 minutes. Some investigators have used similar fractionation techniques, but they limited their observations to cytosolic and membrane fractions. ${ }^{7}$ Still others were exploring different conditions, which highlights how different the changes are that we found to be associated with CDPL. With regard to the isozymes involved, the sites of translo-

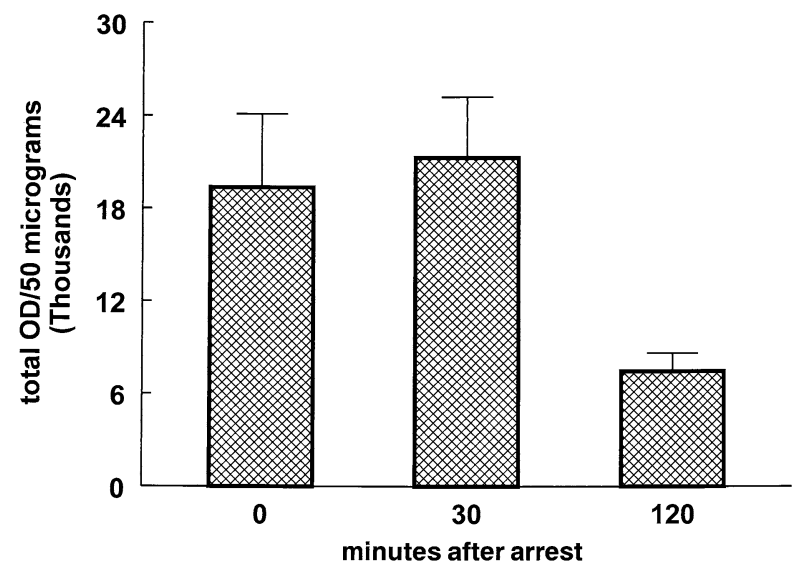

Figure 3. A significant decrease of PKC- $\delta$ total optical density, measured in gross homogenate, suggests PKC degradation over time. Similar changes were seen in PKC- $\epsilon$, but not in PKC- $\alpha$. OD, Optical density.

cation, and the timing of events, our data differ significantly from those reported in warm ischemia ${ }^{15}$ or ischemic preconditioning. ${ }^{16}$ Yoshida and colleagues ${ }^{15}$ demonstrated the presence and translocation of PKC- $\alpha$ from the cytosolic fraction to both the $\mathrm{P} 1$ and $\mathrm{P} 2$ fractions during warm ischemia. Our results differ in that PKC- $\alpha$ translocated early and transiently. The involvement of translocation to the P2 fraction that we observed was also much more limited and may be artifactual because of the ubiquidation of the isozyme earlier associated with the P1 fraction. Similar distinctions between the work of Yohida and colleagues and our data were evident regarding the translocation of PKC- $\delta$ and $-\epsilon$. In distinct contrast to our findings, Ping and colleagues ${ }^{6}$ reported translocation of only PKC- $\epsilon$ after ischemic preconditioning and found no evidence of involvement for PKC- $\delta$ or $-\alpha$. The PKC- $\eta$ isozyme has been detected in rabbit hearts, and there has been some suggestion that PKC- $\eta$ might have an important role in myocardial protection in ischemic preconditioning. ${ }^{16}$ However, we could not detect PKC- $\eta$ at baseline or at any time after CDPL arrest.

The cardioplegic approach we used consistently results in a measurable ventricular contractile deficit. ${ }^{10,12,14}$ The pathophysiology underlying cardioplegia-related ventricular dysfunction is complex. ${ }^{17-20}$ Various experimental models of heart dysfunction have demonstrated that impaired myocardial performance is associated with changes in the distribution of PKC. ${ }^{10,15,21}$ Furthermore, Lu and associates ${ }^{7}$ demonstrated that nonspecific inhibition of all PKC isozymes attenuates or prevents the protection afforded by preconditioning of the heart. Other investigators ${ }^{8,22-24}$ have done extensive work demonstrating roles for both PKC and reactive oxygen species in ischemic preconditioning. However, our evidence indicates that the timing and profile of isozymes involved differ from those seen in warm ischemia 
or ischemic preconditioning, as does the functional response of myofilaments. ${ }^{12}$ This suggests that cold cardioplegic arrest may cause unique changes that should be investigated separately. There is some evidence that increased intracellular PKC or translocation of some isozymes from one site to another is associated with phosphorylation of regulatory contractile proteins (eg, troponin I and troponin T). Specific changes in the phosphorylated state of these proteins could be related to depression of ventricular function ${ }^{21}$ or could contribute to proteolytic degradation. ${ }^{25,29}$ However, it is still unclear which PKC isozymes are predominantly involved and whether the translocation of PKC isozymes, and any resulting dysfunctional consequences, can be prevented.

PKC- $\epsilon$ has recently been identified as playing a critical role in protecting the myocardium against ischemia/reperfusion injury. $6,11,26,27$ However, the involvement of, and role for, other PKC isozymes has not been excluded. Evidence indicates that translocation of PKC- $\epsilon$ from the cytosol to the myofilaments may be protective. ${ }^{28,29}$ Support for this hypothesis has come from independent investigations with ethanol, ${ }^{26}$ ischemic preconditioning, ${ }^{16}$ and cold crystalloid CDPL supplemented with adenosine. ${ }^{10}$ Our data demonstrated a significant increase in PKC- $\epsilon$ concentration in the myofilament fraction at 30 and 60 minutes with cold, crystalloid St Thomas No. 2 cardioplegia. Previous work from our laboratory has demonstrated that when adenosine is added in CDPL solution, translocation of PKC- $\epsilon$ from the cytosolic to particulate fractions is enhanced, ${ }^{10}$ and the hearts are better protected during the arrest period. These data are consistent with the hypothesis that $\mathrm{PKC}-\epsilon$ is protective. However, we also reported that adenosine suppressed the translocation of PKC- $\delta$. It has been suggested that activation of PKC- $\delta$ may be detrimental, ${ }^{28}$ and evidence indicates that activation of PKC can increase the susceptibility of contractile proteins to proteolytic degradation. $^{29}$ The selective, sustained translocation of only the PKC- $\delta$ isozyme during CDPL agrees with our earlier work $^{10}$ and may be involved in this regard. Work to specifically test the role of PKC- $\delta$ has been limited, however, by the lack of specific inhibitors that can be used in the intact organ to concomitantly measure contractile function. We have tried to use rottlerin to specifically inhibit PKC- $\delta$, but the infusion of the compound itself caused severe myocardial depression that would have obscured any functional assessment (data not shown). Future work is needed to investigate this important question.

The temporal differences in isozyme translocation specifically to the cellular fraction containing the myofilament proteins are novel. These data are consistent with our hypothesis that activation of PKC may contribute to the altered myofilament function we have shown to occur in this model of CDPL arrest. The selective translocation of PKC- $\delta$ isozyme during CDPL agrees with our earlier work and differs from that seen under other conditions, such as warm ischemia and ischemic preconditioning. It is clear that the differential PKC responses related with myocardial protection during cardiac operations cannot be extrapolated from the responses seen in other conditions.

\section{References}

1. DeBoer DA, Clark RE. Iron chelation in myocardial preservation after ischemia-reperfusion injury: the importance of pretreatment and toxicity. Ann Thorac Surg. 1992;53:412-8.

2. Johnson JA, Mochly-Rosen D. Inhibition of the spontaneous rate of contraction of neonatal cardiac myocytes by protein kinase C isozymes. A putative role for the epsilon isozyme. Circ Res. 1995;76: 654-63.

3. Robert V, Ayoub S, Berson G. Effects of hydroxyl radicals on ATPase and protein structure of myofibrils from rat heart. Am J Physiol. 1991;261:H1785-90.

4. Loop FD, Higgins TL, Panda R, Pearce G, Estafanous G. Myocardial protection during cardiac operations. J Thorac Cardiovasc Surg. 1992; 104:608-18.

5. Powers FM, Fogelson BG, Sturgeon C, Solaro RJ, Law WR. Depressed myofilament cooperativity associated with post-cardioplegic myocardial depression. J Mol Cell Cardiol. 1998;30:1779-87.

6. Ping P, Zhang J, Pierce WM Jr, Bolli R. Functional proteomic analysis of protein kinase $\mathrm{C}$ epsilon signaling complexes in the normal heart and during cardioprotection. Circ Res. 2001;5:59-62.

7. Lu K, Otani H, Yamamura T, Nakao Y, Hattori R, Ninomiya H, et al. Protein kinase $\mathrm{C}$ isoform-dependent myocardial protection by ischemic preconditioning and potassium cardioplegia. J Thorac Cardiovasc Surg. 2001;121:137-48.

8. Tosaki A, Maulik N, Engelman DT, Engelman RM, Das DK. The role of protein kinase $\mathrm{C}$ in ischemic/reperfused preconditioned isolated rat hearts. J Cardiovasc Pharmacol. 1996;28:723-31.

9. Mochly-Rosen D, Gordon AS. Anchoring proteins for protein kinase C: a means for isozyme selectivity. FASEB J. 1998;12:35-42.

10. Nawas SI, Schwertz DW, Beck JM, Fogelson BG, Law WR. Mechanisms of myocardial protection by adenosine-supplemented cardioplegia: differential response of calcium-independent protein kinase $\mathrm{C}$ isozymes. J Surg Res. 2000;89:163-8.

11. Liu GS, Cohen MV, Mochly-Rosen D, Downey JM. Protein kinase $\mathrm{C}$-epsilon is responsible for the protection of preconditioning in rabbit cardiomyocytes. J Mol Cell Cardiol. 1999;31:1937-48.

12. Fogelson BG, Nawas SI, Law WR. Mechanisms of myocardial protection in adenosine-supplemented cardioplegia: myofilament and metabolic responses. J Thorac Cardiovasc Surg. 2000;119:601-9.

13. Laemmli UK. Cleavage of structural proteins during the assembly of the head of bacteriophage T4. Nature. 1970;227:680-5.

14. Powers FM, Fogelson BG, Sturgeon C, Solaro RJ, Law WR. Depressed myofilament cooperativity associated with post-cardioplegic myocardial depression. J Mol Cell Cardiol. 1998;30:1779-87.

15. Yoshida K, Hirata T, Akita Y, Mizukama Y, Yamaguchi K, Sorimachi Y, et al. Translocation of protein kinase C-alpha, delta and epsilon isoforms in ischemic rat heart. Biochim Biophys Acta. 1996;1317:3644.

16. Ping $\mathrm{P}$, Zhang J, Qui Y, Tang X, Manchikalapudi S, Cao X, et al. Ischemic preconditioning induces selective translocation of protein kinase $\mathrm{C}$ isoforms epsilon and eta in the heart of conscious rabbits without subcellular redistribution of total protein kinase $\mathrm{C}$ activity. Circ Res. 1997;81:404-14.

17. Jovanovic A, Lopez JR, Alekseev AE, Shen WK, Terzic A. Adenosine prevents $\mathrm{K}^{+}$-induced $\mathrm{Ca}^{2+}$ loading: insight into cardioprotection during cardioplegia. Ann Thorac Surg. 1998;65:586-91.

18. Piper HM, Garcia-Dorado D. Prime causes of rapid cardiomyocyte death during reperfusion. Ann Thorac Surg. 1999;68:1913-9.

19. Park JL, Lucchesi BR. Mechanism of myocardial reperfusion injury. Ann Thorac Surg. 1999;68:1905-12.

20. Thourani VH, Ronson RS, Van Wylen DGL, Shearer ST, Katzmark SL, Zhao Z, et al. Adenosine-supplemented blood cardioplegia atten- 
uates postischemic dysfunction after severe regional ischemia. Circulation. 1999;100(suppl 2):376-83.

21. Giles TDN, Ouyang J, Kerut K, Given MB, Allen GE, Mcilwain EF, et al. Changes in PKC in early cardiomyopathy and in gracilis muscle in the BB/Wor diabetic rat. Am J Physiol.. 1998;274(1 Pt 2):H295-307.

22. Das DK, Engelman RM, Maulik N. Oxygen free radical signaling in ischemic preconditioning. Ann N Y Acad Sci. 1999;874:49-65.

23. Das DK, Maulik N, Sato M, Ray PS. Reactive oxygen species function as second messenger during ischemic preconditioning of heart. Mol Cell Biochem. 1999;196:59-67.

24. Hattori R, Otani H, Uchiyama T, Imamura H, Cui J, Maulik N, et al. Src tyrosine kinase is the trigger but not the mediator of ischemic preconditioning. Am J Physiol Heart Circ Physiol. 2001;281:H106674.

25. Tanaka Y, Kashiwagi A, Ogawa T, Abe N, Asahina T, Ikebuchi M, et al. Effect of verapamil on cardiac protein kinase $\mathrm{C}$ activity in diabetic rats. Eur J Pharmacol. 1991;200:353-6.

26. Chen C, Gray MO, Mochly-Rosen D. Cardioprotection from ischemia by a brief exposure to physiological levels of ethanol: role of epsilon protein kinase C. Proc Natl Acad Sci U S A. 1999;96:12784-9.

27. Dorn GW, Souroujon MC, Liron T, Chen C, Gray MO, Zhou H, et al. Sustained in vivo cardiac protection by a rationally designed peptide that causes epsilon protein kinase C translocation. Proc Natl Acad Sci U S A. 1999;96:12798-803.

28. Mochly-Rosen D, Kauvar LM. Modulating protein kinase C signal transduction. Adv Pharmacol. 1998;44:91-145.

29. Di Lisa F, De Tullio R, Salamino F, Barbato R, Melloni E, Siliprandi $\mathrm{N}$, et al. Specific degradation of troponin $\mathrm{T}$ and $\mathrm{I}$ by mucalpain and its modulation by substrate phosphorylation. Biochem J. 1995;308:57-61

\section{Targeted}

The Journal of Thoracic and Cardiovascular Surgery gives you two tables of contents.

The condensed table of contents tells you at a glance what topics and authors are presented each month. The expanded table of contents gives you a brief abstract of each article. You select only those articles of most interest to you for further reading. 